\title{
Malignant Transformation of Ménétrier Disease: Case Report and Review of the Literature
}

\author{
F. Haddar ${ }^{1 *}$, J. Elatmani ${ }^{1}$, F. Bellouhou ${ }^{1}$, A. Ait Errami ${ }^{1}$, S. Oubaha ${ }^{2}$, Z. Samlani ${ }^{1}$, K. Krati $^{1}$
}

${ }^{1}$ Department of Gastroenterology, Mohammed VI University Hospital, Marrakech, Morocco

${ }^{2}$ Department of Physiology, Faculty of Medicine and Pharmacy at Cadi Ayyad University, Marrakech, Morocco

DOI: $10.36347 /$ simcr.2020.v08i02.015

| Received: 20.01.2020 | Accepted: 27.01.2020 | Published: 14.02.2020

*Corresponding author: F. Haddar

Abstract

Ménétrier's disease is an infrequent hypertrophic disease of the stomach associated with hypoproteinemia of unknown etiology. This disease is considered to be premalignant since 10-15\% of affected individuals develop gastric cancer. We report the case of a malignant degeneration of Ménétrier disease associated with gastric polyposis in a 60-yearsold man who had received a diagnosis of Ménétrier's disease 4 years previously and who was found to have advanced antral gastric cancer during the follow-up. We provide an update on the optimal therapeutic approach, which has not been clearly defined to date.

Keywords: Hypertrophic gastritis - Ménétrier disease - Cancer - Stomach.

Copyright @ 2020: This is an open-access article distributed under the terms of the Creative Commons Attribution license which permits unrestricted use, distribution, and reproduction in any medium for non-commercial use (Non Commercial, or CC-BY-NC) provided the original author and source are credited.

\section{INTRODUCTION}

Menetrier's disease (MD) is a rare disease that was first described by the French pathologist Pierre Menetrier in 1888 [1]. It is a rare acquired hypertrophic gastropathy leading to dilatation of the mucus-secreting gastric pits (fovula) on the expense of the gastric glands containing the acid-producing parietal cells and pepsinogen-producing chief cells which undergoes atrophy. These changes gives the disease it characteristic features of the huge expansion of gastric mucosa, thick mucus secretion, protein loss and hypochlorhydria [2]. The disease is more dominant in middle-aged males [3] but several authors reported it in pediatric population [4]. The etiology is not well established. Some theories tried to link it to Helicobacter pylori (H. pylori) infection [5] and enhanced gastric epidermal growth factor receptor signaling by transforming growthfactor-alpha [1]. The clinical picture includes epigastric pain and discomfort, nausea, vomiting and peripheral edema due to low serum albumin levels. MD has a recognized premalignant potential [6-8]. Also it can lead to severe uncontrollable protein loss orupper GIT bleeding [8]. Medical treatment of MD includes proton pump inhibitors, high-protein diet, eradication of $\mathrm{H}$. pylori [5], cetuximab (monoclonalantibody) [6] and octreotide long-acting release [4]. Also total and partial gastrectomy are attempted in managing resistant cases.We describe a case of MD with an unusual presentation that wasrecently managed in our hospital. We present a new case of Ménétrier disease (MD) associated with gastric cancer.

\section{Clinical Case}

A 60-year-old male with Ménétrier disease (MD) diagnosed 4 years earlier. In the endoscopy that was performed, a large area of thickened folds was observed in the greater curvature, compatible with MD. The biopsy confirmed the endoscopic suspicion. The patient refused surgical treatment and chose medical treatment and endoscopic follow-up, without having presented remarkable changes. He advanced his annual appointment, since he presented heaviness and epigastric pain, retrosternal heartburn, dark vomiting, hematemesis, ascites with a peripheral edema and weight loss. Endoscopy were performed, very thickened folds were observed in both curvatures and also the duodenal walls, with a very hyperemic mucosa and multiple ulcers, signs of recent bleeding, without any macroscopic mass or stenosis. Biopsies were released and the histological microscopy corresponds to an adenocarcinoma. Low protein ascites without any neoplasic cells, total proteins $4.1 \mathrm{~g} \mathrm{/} \mathrm{dl}$, anemia hemoglobin 10,6 g/dl, hypokaliemia $2,8 \mathrm{mmol} / \mathrm{l}$ and lactate dehydrogenase $288 \mathrm{IU} / 1$. Abdominal computed tomography was performed, and who objectified extensive gastric thickening of the cardia, large curvature and pylorus, stenosing and locally infiltrating. 
Associated with a circumferential and irregular thickening of D2 and D3, stenosing and locally infiltrating and responsible for dilation of the pancreatic ducts. A peritoneal effusion of great abundance. Multiples lung nodules, without any hepatic nodules. And so it was decided to perform palliative surgery using gastroenteroanastomosis. And biopsies of the lung nodules. The gastric biopsies show the typical histological aspect of MD (hyperplastic gastropathy with hypertrophy foveolar), and the lung lesion is compatible with adenocarcinoma. In the postoperative follow-up he presented 3 episodes of low abundance hematemesis. He died 3 months after the intervention due to progression of the neoplasm.
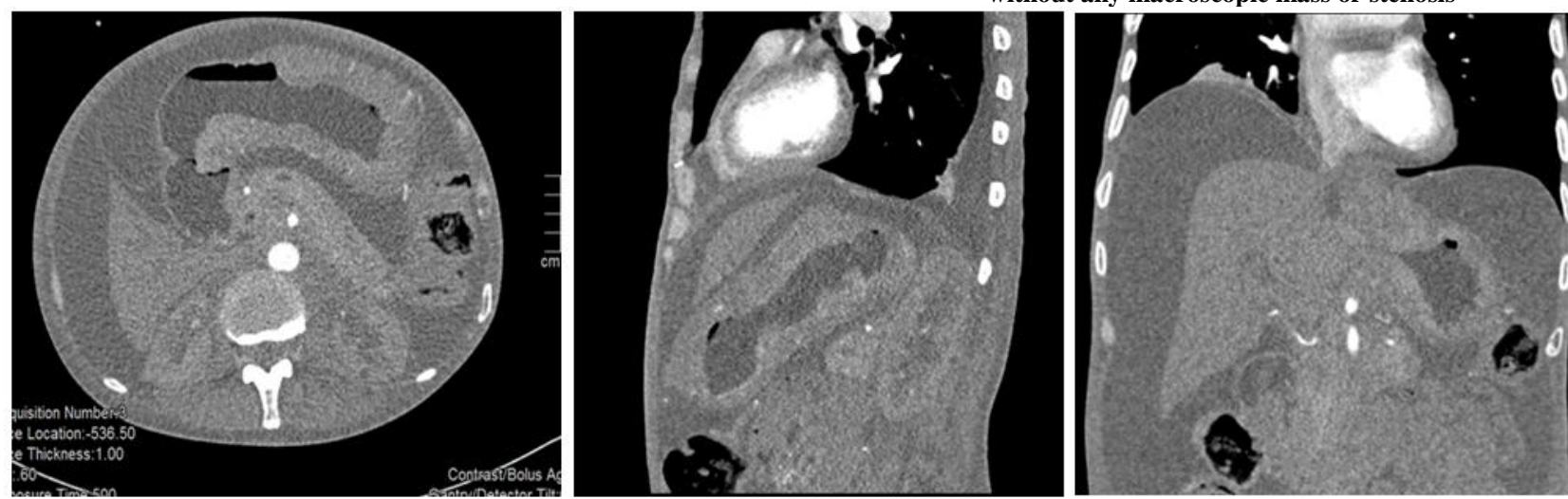

Fig-2: CT in axial sections with sagittal and coronal reconstruction: Thickening of the large and the small curvature extended to the cardia

\section{DiscuSSION}

A condition described for the first time by Pierre Ménétrier in 1888, Ménétrier's disease, also called giant hypertrophic gastritis or hypertrophic hypoproteinemic gastropathy, is a precancerous condition. If the cause remains unknown, an expression of the epidermal growth factor has been demonstrated on the cells of the pathological gastric mucosa. The condition occurs readily in men in their forties. Exceptionally, it occurs in children where it is linked to cytomegalovirus infection [9]. The condition affects the fundus and the stomach body but most often spares the gastric antrum [10] as is the case in our observation. However, localized forms have been described [11].

The clinical signs are dominated by digestive symptoms (nausea, vomiting, hematemesis), weight loss, peripheral edema or even an anasarca related to hypoprotidemia and hypoalbuminemia [12]. In our observation, epigastric pain, ascites and peripheral edema, and hematemesis were the warning signs, the diagnosis being made on the basis of a clinicopathological and biological correlation (hypoprotidemia is considered as a corner stonein the diagnosis) [2]. However, anemia is a sign frequently found in $70 \%$ of cases. In patients with MD there seems to be a higher incidence of serious infections and thromboembolic diseases.
On endoscopy, a thickening of the gastric folds or nodular thickening of the mucosa is observed macroscopically, and a biopsy of the entire thickness of the affected mucosa should be performed. Microscopically there is an increase in epithelial thickness, foveolar hyperplasia, glandular atrophy and a mild inflammatory infiltrate [13]. As for the malignant degeneration of MD, it would occur between 8 and $14 \%$ in one aid 1 to 5 years [7].

Abdominal computed tomography shows the thickened folds usually located in the fundus and the greater curvature [8, 14]. A differential diagnosis should be considered with other gastric diseases that can cause thickening of folds: Zollinger-Ellison syndrome, Stiempen syndrome, chronic lymphocytic gastritis, syphilis, sarcoidosis, lymphoma and diffuse infiltrating carcinoma (Bormann IV) $[8,15,16]$.

The risk of malignancy of MD is controversial. As there are only isolated cases or short series, reliable epidemiological data cannot be obtained. The concurrence of gastric cancer and published MD ranges from $0-10 \%$. But it is difficult to assess in the literature whether it really is a malignancy of MD or a coincident cancer [7, 8]. The treatment of MD is not clearly established.

Several drug treatments based on anti cholinergics, octreotide, antacids, prednisone, and the 
eradication of Helicobacter pylori have been proposed for the treatment of MD with unsatisfactory results $[4,5]$. Relapse generally occurs when treatment is stopped, except in children where spontaneous regressions after a few weeks have been observed [1]. The use of monoclonal antibodies such as cetuximab which inhibits growth factor has made it possible to stop anemia in certain patients and constitutes an alternative when gastric resection is contraindicated [4, 6, 17, 16]. However, in cases with major symptomatology (uncontrollable loss of protein or bleeding) or a fortiori in case of degeneration, the surgical treatment is offered. Total gastrectomy, a radical gesture, allows better survival, especially in this superficial form of cancer associated with polyposis where polypectomy or even mucosectomy involves the risk of allowing a small cancer to develop. The feasibility of this laparoscopic gastrectomy has been demonstrated [18]. Supporters of total gastrectomy they defend its realization because the risk of malignization is eliminated, the usual location is fundic, and the performance of an anastomosis with a hypertrophied mucosa is avoided [8].

On the contrary, the defenders of a more economic surgery affirm that it allows to control the symptoms with less morbidity. Perhaps the most reasonable position is to adapt the technique to the location of MD and the degree of dysplasia. In diffuse cases, located near the heart, as usually occurs, or with dysplasia / neoplasia, total gastrectomy is the technique to be performed. In contrast, in antral lesions without signs of dysplasia, subtotal gastrectomy is sufficient.

\section{Conclusion}

Ménétrier's disease is rare in Africa. Total gastrectomy remains the best gesture to propose in case of malignant transformation of this affection. It is necessary to monitor the gastric mucosa via routine endoscopy on the follow-up of patients who has been diagnosed with MD. Treatment with octreotide had little effect on the gastric mucosa, while antimicrobial combination therapy provided no benefit in $\mathrm{H}$. pylori-negative and if the patient is concerned about the potential development of cancer, a partial or total gastrectomy is recommended.

\section{REFERENCES}

1. Coffey Jr RJ, Tanksley J. Pierre Ménétrier and his disease. Transactions of the American Clinical and Climatological Association. 2012;123:126.

2. Rich A, Toro TZ, Tanksley J, Fiske WH, Lind CD, Ayers GD, Piessevaux H, Washington MK, Coffey RJ. Distinguishing Ménétrier's disease from its mimics. Gut. 2010 Dec 1;59(12):1617-24.

3. Sweeney AR, Lynch MK. A case of Ménétrier's disease localized to the gastric antrum without helicobacter infection or hypoalbuminemia.
International journal of surgery case reports. 2013 Jan 1;4(10):839-41.

4. Di Nardo G, Oliva S, Aloi M, Ferrari F, Frediani S, Marcheggiano A, Cucchiara S. A pediatric nonprotein losing Menetrier's disease successfully treated with octreotide long acting release. World Journal of Gastroenterology: WJG. 2012 Jun $7 ; 18(21): 2727$.

5. Fretzayas A, Moustaki M, Alexopoulou E, Nicolaidou P. Menetrier's disease associated with Helicobacter pylori: three cases with sonographic findings and a literature review. Annals of tropical paediatrics. 2011 May 1;31(2):141-7.

6. Fiske WH, Tanksley J, Nam KT, Goldenring JR, Slebos RJ, Liebler DC, Abtahi AM, La Fleur B, Ayers GD, Lind CD, Washington MK. Efficacy of cetuximab in the treatment of Menetrier's disease. Science translational medicine. 2009 Nov 25;1(8):8ra18-.

7. Jouini M, Ksontini R, Kacem MJ, Haouet S, Ammous A, Gargouri F, Houissa H, Ben ZS, Ammar AB, Belaid S. Menetrier disease associated with a gastric adenocarcinoma. Apropos of 2 cases. InAnnales de gastroenterologie et d'hepatologie 1996; 31(6):341-345.

8. Kim J, Cheong JH, Chen J, Hyung WJ, Choi SH, Noh SH. Ménétrier's disease in Korea: report of two cases and review of cases in a gastric cancer prevalent region. Yonsei medical journal. 2004 Jun 1;45(3):555-60.

9. Cardona AB, Sorní AH, Hostalot AA, Rosal JR, Mercé JG, Izuel JN. Ménétrier's disease of childhood and acute cytomegalus virus infection. InAnales de pediatria (Barcelona, Spain: 2003) 2006 May ; 64(5):478-80.

10. Charton-Bain MC, Paraf F, Bruneval P. Superficial gastric carcinoma developed on localized hypertrophic lymphocytic gastritis: a variant of localized Menetrier's disease? Pathology-Research and Practice. 2000 Jan 1;196(2):125-8.

11. Lambrecht NW. Ménétrier's disease of the stomach: a clinical challenge. Curr Gastroenterol Rep. 2011 Dec;13(6):513-7.

12. Fernández CV, Abad A, Serrano A, Colina F, Ibarrola C, Alcalde J, Ibarra A, Morales C. Enfermedad de Menetrier localizada en gemelos monocigóticos. Cirugía Española. 2002 Jan 1;72(4):246.

13. Roseau G, Leport J, Cerf $M$. Dégénérescence maligne d'une maladie de Ménétrier. InAnnales de gastroénterologie et d'hépatologie 1987; 23(5), 247-249.

14. Takaya J, Kawamura Y, Kino M, Kawashima Y, Yamamoto A, Kobayashi Y. Menetrier's disease evaluated serially by abdominal ultrasonography. Pediatric radiology. 1997 Feb 1;27(2):178-80.

15. Ba-Ssalamah A, Prokop M, Uffmann M, Pokieser P, Teleky B, Lechner G. Dedicated multidetector 
CT of the stomach: spectrum of diseases. Radiographics. 2003 May;23(3):625-44.

16. Burdick JS, Chung E, Tanner G, Sun M, Paciga JE, Cheng JQ, Washington K, Goldenring JR, Coffey RJ. Treatment of Menetrier's disease with a monoclonal antibody against the epidermal growth factor receptor. New England Journal of Medicine. 2000 Dec 7;343(23):1697-701.

17. Settle SH, Washington K, Lind C, Itzkowitz S, Fiske WH, Burdick JS, Jerome WG, Ray M, Weinstein W, Coffey RJ. Chronic treatment of
Menetrier's disease with Erbitux: clinical efficacy and insight into pathophysiology. Clinical Gastroenterology and Hepatology. 2005 Jul 1;3(7):654-9.

18. Byun J, Kwon S, Oh SY, Lee KG, Suh YS, Kong SH, Kim SG, Kim WH, Yang HK, Lee HJ. Laparoscopic management of hypertrophic hypersecretory gastropathy with protein loss: a case report. Asian journal of endoscopic surgery. 2014 Jan;7(1):48-51. 